\title{
Design and Implementation of I-PD Controller for DC Motor Speed Control System by Adaptive Tabu Search
}

\author{
Thanet Ketthong and Satean Tunyasirut \\ Department of Electrical Engineering, Faculty of Engineering, Pathumwan Institute of Technology, \\ Bangkok, 10330 Thailand \\ E-mail: netgoldgear@gmail.com, satean@pit.ac.th \\ Deacha Puangdownreong* \\ Department of Electrical Engineering, Graduate School, Southeast Asia University, Bangkok, 10160 Thailand \\ Corresponding Author: E-mail: deachap@sau.ac.th
}

Received: 23 April 2017; Accepted: 06 June 2017; Published: 08 September 2017

\begin{abstract}
One of the modified versions of the PID controller is the I-PD controller. It was proposed for eliminating the proportional and derivative kick appeared during set point change. In this paper, the optimal I-PD controller design for DC motor speed control system by the adaptive tabu search (ATS), one of the most efficient metaheuristic optimization techniques, is proposed. In a control system, DC motor is the principle and it is widely used because of the power from existing direct-current lighting power distribution systems. It can be controlled over a wide range and a variable supply. In this research, TMS320F28335 DSP microcontroller is implemented for DC motor speed control. This processor consists of the several peripheral circuits for motor drive application such as analog to digital, encoder digital to analog and PWM input/output interface circuits. These interface circuits can be used in both of DC and AC motor controls. For the control algorithm development and the Code Composer Studio (CCS) compiler can be used together with TMS320F28335 DSP in MATLAB/SIMULINK. This proposed method is tested with the DC motor, 1260, $1400,1540 \mathrm{rpm}$ and 24 volts, consecutively to verify the performance of the I-PD controller designed for DC motor speed control system using the speed and control signal response to many load disturbances. The simulation of DC motor is based on MATLAB/SIMULINK. The implementation results are compared with the simulation results. The correlation in the experiment shows that they are high related. In this paper show the effectiveness of the proposed methods and discuss how they could generalize to other systems by the simulation and experimentation. The results show that the I-PD parameters can be optimized by the ATS. The controlled system with I-PD provides better responses once compared to that with a basic parallel PID controller.
\end{abstract}

Index Terms - Adaptive Tabu Search, I-PD Controller, DC Motor Speed Control, Metaheuristic Optimization.

\section{INTRODUCTION}

The proportional-integral-derivative (PID) controller was firstly proposed in 1922 by Minorsky [1] and firstly applied for industrial applications in 1939 [2]. The PID controller is a control loop feedback mechanism (controller) and widely used in industrial control systems.

The PID controller calculates the error value of the difference between a measured process variable and a desired set point. The PID controller algorithm involves three separate constant parameters, and is accordingly sometimes called three term control: the proportional, the integral and derivative values, may be denoted by P, I, \& D. Simply put, these values can be interpreted in terms of time: $\mathrm{P}$ depends on the present error, I on the accumulation of past errors, and D is a prediction of future errors, based on current rate of change. The weighted sum of these three actions is used to adjust the process via a control element such as the position of a control valve $[3,4,5]$. Due to ease of use and simple realization, the PID controllers have been increasingly employed in the feedback control system over decades. However, the major drawbacks of the basic parallel PID controllers are the effects of proportional and derivative kick. In order to reduce these effects, one of the modified versions of the PID controller called the I-PD controller was proposed [6]. By literatures, many analytical design methods for the I-PD were consecutively launched, for examples, the generalized predictive control law [7], the coefficient ratio assignment (CRA) method [8], the coefficient diagram method (CDM) [9] the integral-type optimal servomechanism [10] and the generalized Kalman-Yakubovich-Popov (GKYP) lemma [11]. Recently, the control design framework has been changed to new paradigm known as the parameter optimization problem. The metaheuristic optimization search techniques have been widely applied to design the I-PD controller, such as fuzzy logic based [12, 13], particle 
swarm optimization (PSO) [14, 15], bacterial foraging algorithm (BFA) [16] , differential evolution (DE) [17] and multi objective particle swarm optimization [18]. Among those metaheuristic techniques, the adaptive tabu search (ATS) is one of the most powerful techniques [19]. The ATS was developed as a modified version of the original tabu search. The convergence analysis and the performance evaluation of the ATS were reported [19]. By literatures, the ATS has been successfully applied to various engineering problems, for examples, electrical system protection [20], dynamical system identification [21] and control synthesis [22]. In this paper, the ATS is applied to design an optimal I-PD controller for a DC motor speed control system. The results obtained will be compared those with the basic parallel PID controller.

This paper consists of seven sections. After an introduction given in section I, the related works of I-PD optimization are presented in section II. Details of ATS algorithms are illustrated in section III. The problem formulation of the PID and I-PD via the standard basic control loop is described in section IV. Application of the ATS to I-PD controller optimization for the DC motor speed control system is provided in section V. Simulation and experimental results are illustrated section VI, while conclusions are given in section VII.

\section{RELATED WORKS OF I-PD OPTIMIZATION}

The I-PD controller design optimization for DC motor speed control by the ATS can be represented by the block diagram in Fig. 1. The sum-squared error between $R(s)$ and $C(s)$ is set as the objective function $J$ expressed in (1). $J$ will be fed back to the ATS tuning block to be minimized in order to find the optimal I-PD parameters satisfying to the inequality constraints stated in (2), where $M_{p}$ and $E_{s s}$ are maximum overshoot and steady-state error, $K_{p}, K_{i}$ and $K_{d}$ are the proportional, integral and derivative gains, respectively.

$$
\left.\begin{array}{ll}
\text { Minimize } & J=\sum_{i=1}^{N}[r(i)-c(i)]^{2} \\
\text { subject to } & M_{p} \leq 10 \%, \\
& E_{s s} \leq 0.1 \%, \\
& 10 \leq K_{p} \leq 100, \\
& 300 \leq K_{i} \leq 600, \\
& 0.1 \leq K_{d} \leq 2.0
\end{array}\right\}
$$

The use of AI search techniques to design the I-PD controller can be represented by the block diagram in Fig. 1. The cost function, $J$, the sum of absolute errors between $R(s)$ and $C(s)$ as stated in (1), is fed back to the AI tuning block. $J$ is minimized to find the optimum I-PD controller's parameters. In this work, the AI tuning block contains the ATS algorithm.

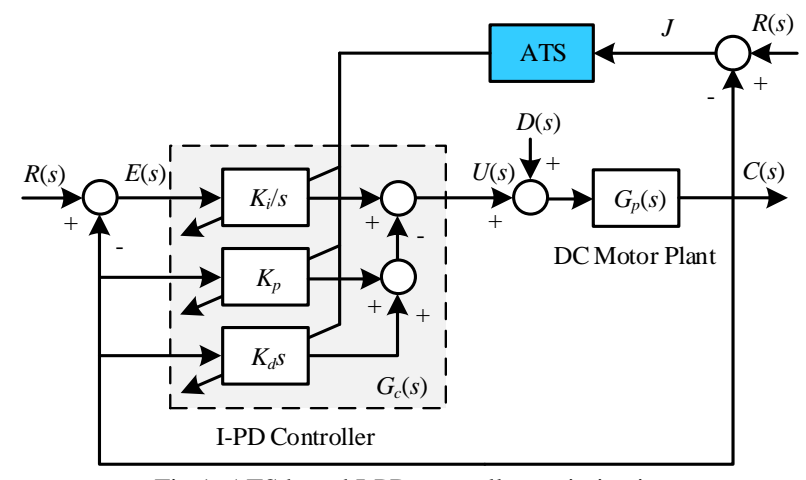

Fig.1. ATS based I-PD controller optimization.

\section{Adaptive Tabu Search Algorithms}

As a modified version of the original tabu search, the adaptive tabu search (ATS) is based on the neighborhood search approach. The ATS possesses the tabu list (TL), back-tracking (BT) and adaptive search radius (AR) mechanisms [19]. The TS is used to record the visited solutions. The BT is conducted to escape the local entrapment towards a new search path by using the data stored in the TL. Once a current solution is close to a local minimum, the $\mathrm{AR}$ is activated by reducing the search radius in order to speed up the search process. The algorithms of the ATS can be described step-by-step as follows:

Step 1. Initialize a search space, count and count $_{\max }$ (maximum search round).

Step 2. Randomly select an initial solution $x_{0}$ from the search space. Let $x_{0}$ be a current local minimum.

Step 3. Randomly generate $n$ solutions around $x_{0}$ within a certain radius $R$. Store the $n$ solutions called neighborhood in a set $X$.

Step 4. Evaluate an objective function $f(\cdot)$ of each member in $X$. Set $x_{1}$ as a solution that gives the minimum objective function in $X$.

Step 5. If $f\left(x_{1}\right)<f\left(x_{0}\right)$, put $x_{0}$ into the TL and set $x_{0}=x_{1}$, otherwise, store $x_{1}$ in the TL instead.

Step 6. Activate the BT mechanism, when local entrapment occurs.

Step 7. Invoke the AR mechanism, when the search moves close to a local minimum by adjusting $R$ $=\mu R, 0<\mu<1$.

Step 8. If the termination criteria (TC): count $\geq$ count $_{\max }$, or desired specifications are met, stop the search process. $x_{0}$ is the best solution found, otherwise update count, and go back to Step 2.

The ATS method [23, 24] is one of the most efficient AI search techniques. It is based on the iterative neighborhood search approach for solving combinatorial and nonlinear problems. The Tabu list, one important feature of the method that has first in-last-out property, is used to record a history of solution movement for leading a new direction that can escape a local minimum trap. In addition, the ATS method has two additional mechanisms, 
namely backtracking and adaptive search radius, to enhance its convergence.

The backtracking mechanism described in Step 6 is active when the number of solutions cycling is equal to the maximum solution-cycling allowance. This mechanism selects an already visited solution stored in the TL as an initial solution for the next search The round to enable a new search path that could escape the local deadlock towards a new local minimum. For the AR mechanism described in Step 7, it is invoked when a current solution is relatively close to a local minimum. The radius is thus decreased in accordance with the best cost function found so far. The less the cost function, the smaller the radius. With the two features, a sequence of solutions obtained by the ATS method rapidly converges to the global minimum. The ATS algorithm can be summarized by the pseudo code as shown in Fig. 2 .

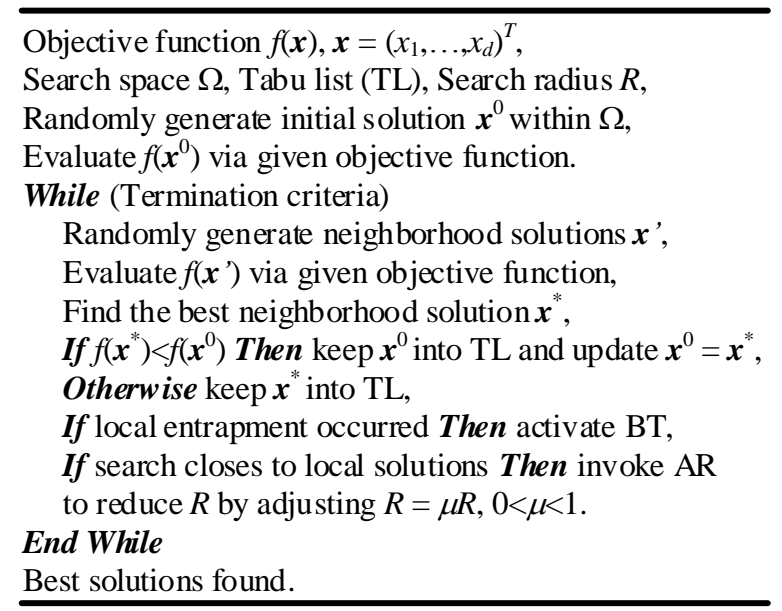

Fig.2. Pseudo code of the ATS algorithm

\section{PROBLEM FORMULATION}

\section{A. Basic Parallel PID Control Loop}

A conventional feedback control loop with basic parallel PID controller is represented by the block diagram in Fig. 3, where $G_{p}(s)$ and $G_{c}(s)$ are the plant and the PID controller transfer functions, respectively. The PID controller receives error signal $E(s)$ and generates control signal $U(s)$ to controlled output $C(s)$ and regulate disturbance $D(s)$ referring to referent input $R(s)$. The time-domain and $s$-domain functions of the PID controller is stated in (3)-(4).

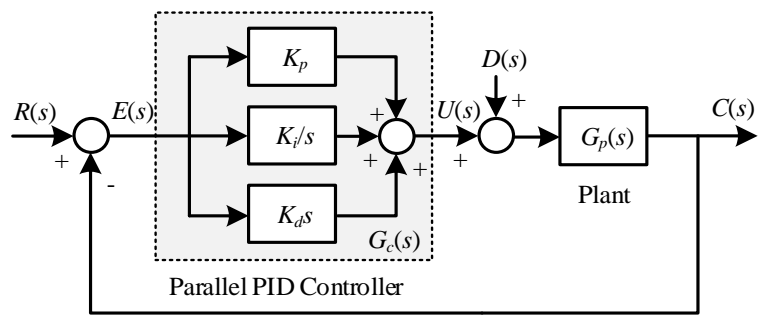

Fig.3. Conventional feedback control loop with basic parallel PID.

$$
\begin{gathered}
\left.u(t)\right|_{P I D}=K_{p} e(t)+K_{i} \int e(t) d t+K_{d} \frac{d e(t)}{d t} \\
\left.G_{c}(s)\right|_{P I D}=K_{p}+\frac{K_{i}}{s}+K_{d} s \\
\frac{C(s)}{R(s)}=\frac{\left(K_{p}+\frac{K_{i}}{s}+K_{d} s\right) G_{p}(s)}{1+\left(K_{p}+\frac{K_{i}}{s}+K_{d} s\right) G_{p}(s)}
\end{gathered}
$$

The closed loop transfer function with basic parallel PID controller is given in (5). The main control objective is to make $C(s)=R(s)$. By this objective, the controller continuously adjusts the control signal $U(s)$ until the error $E(s)$ is zero irrespective of the disturbance signal $D(s)$. By using parallel PID controller, a step change in the reference input $R(s)$ will cause an immediate spiky change in the control signal $U(s)$. This abrupt change in the controller output is known as the proportional and derivative kick (or shortly set-point kick). This kick effects rapidly change the command signal to the actuator which controls the entire operation of the plant $G_{p}(s)$ [6]. To overcome this drawback, the I-PD controller is proposd.

\section{B. I-PD Control Loop}

The I-PD controller is one of the modified versions of the PID controller. It is developed to avoid the set-point kick and reduce undesirable overshoot. The feedback control loop with I-PD controller is represented by the block diagram in Fig. 4. Referring to Fig. 4, the integral part is still placed in the forward path, while the proportional and derivative parts are moved to feedback path of the control loop. By this scheme, only the integral term $K_{i}$ responds on the error signal $E(s)$. An abrupt change in the reference input $R(s)$ will not affect the proportional $K_{p}$ and derivative $K_{d}$ terms, since they work on the controlled output $C(s)$. The time-domain function of the I-PD control signal is stated in (6) and the closed loop transfer function with I-PD controller is given in (7).

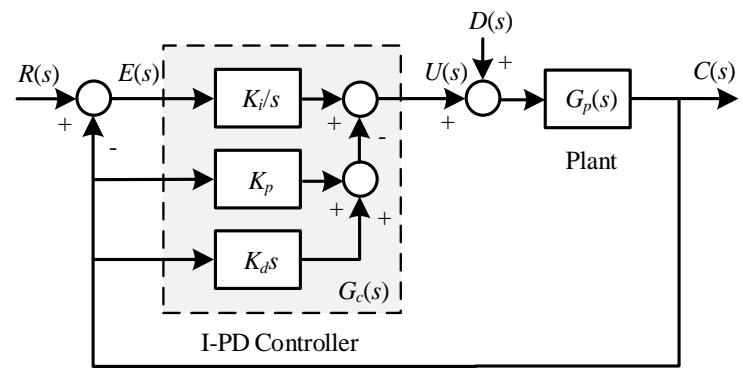

Fig.4. Feedback control loop with I-PD

$$
\left.u(t)\right|_{I-P D}=K_{i} \int e(t) d t-\left(K_{p} c(t)+K_{d} \frac{d c(t)}{d t}\right)
$$




$$
\frac{C(s)}{R(s)}=\frac{\left(\frac{K_{i}}{s}\right) G_{p}(s)}{1+\left(K_{p}+\frac{K_{i}}{s}+K_{d} s\right) G_{p}(s)}
$$

\section{DC-Servo Motor}

The direct current (DC) servo motor is widely used in industry especially in high precision control such as robot arm and disk drive applications [25]. Regarding to control engineering context, analysis and design of the DC-servo motor control system require its accurate model parameters. Generally, such the parameters can be obtained by the blocked-rotor, no-load and retardation tests [26]. However, obtained parameters by these tests often inaccurate due to its uncertainty and error in testing process [26]. Another approach to obtain the model parameters is called the identification approach. Traditionally, model and parameter identification requires the knowledge of system input and output which can be obtained from the particular tests [27, 28]. The model parameters are then obtained by the regression analysis. By this approach, the obtained models are known as the black-box ones consisting of ARX, ARMAX, OE, and BJ, respectively [29]. By literatures, the conventional identification approach has been widely used to linear [30] and nonlinear system [31]. Although their closed-form formulation provide an advantage leading to fast computation, its major drawback is the restriction of the class of models to be difference equations and the like. Moreover, it is not possible to apply the method to identify models of other forms. To-date, metaheuristic optimization techniques have become potential candidates to various engineering applications. Among the trajectory-based metaheuristic optimization techniques, the adaptive tabu search (ATS) is one of the most efficient methods. The ATS has been launched in $2004[32,33]$ as a modified version of the conventional tabu search for solving various engineering optimization problems especially in control synthesis and design problems [34, 35]. From our previous work [36, 37], the ATS-based model parameter identification of a DC-servo motor is presented method. The proposed identification approach can be considered as a class of metaheuristic optimization problems. Results obtained by the ATS will be compared with those obtained by the genetic algorithm (GA), one of the well-known and widely accepted population-based metaheuristic techniques.

\section{DC-Servo Motor Model}

The schematic diagram of armature-controlled DCservo motor can be represented by Fig. 5 [38, 39], where $R_{a}$ is an armature-winding resistance, $L_{a}$ is an armaturewinding inductance, $R_{f}$ is a field-winding resistance, $L_{f}$ is a field-winding inductance, $J$ is a moment of inertia, $B$ is a viscous-friction coefficient, $e_{a}(t)$ is an applied armature voltage, $i_{a}(t)$ is an armature current, $e_{f}(t)$ is a field voltage, $i_{f}(t)$ is a field current, $e_{b}(t)$ is a back emf (electromotive force) voltage, $T(t)$ is a motor torque, $\theta(t)$ is an angular displacement and $\omega(t)$ is an angular velocity (speed), respectively. The $e_{a}(t)$ is considered as the system input and $\omega(t)$ stands for the system output. Referring to Fig. 5, the applied armature voltage $e_{a}(t)$, for the electrical part, can be formulated as expressed in Eq.(8), where $K_{b}$ is back emf constant. For the rotational mechanical part, the motor torque $T(t)$ is performed as stated in Eq.(9), where $K_{t}$ is motor constant.

In practical, the DC-servo motor is usually driven by the power amplify (power electronic devices) which can be approximated by the power amplifier constant $K_{A}$. Therefore, the math model of armature-controlled DCservo motor speed control in term of the transfer function can be formulated by taking differential equations and Laplace transform as expressed in (10). The plant $G_{p}(s)$ of the DC-servo motor can be identified via MATLAB and system identification toolbox. The second-order transfer function model obtained by this approach can be expressed in (11).

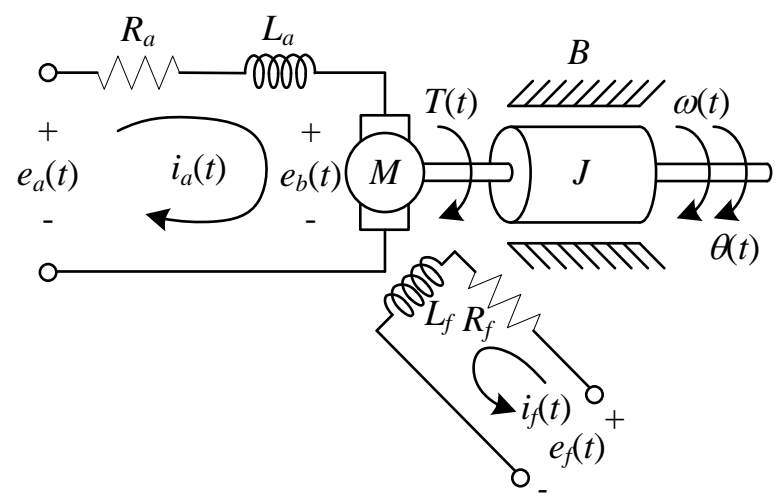

Fig.5. Schematic diagram of DC motor.

$$
\left.\begin{array}{c}
e_{a}(t)=R_{a} i_{a}(t)+L_{a} \frac{d i_{a}(t)}{d t}+e_{b}(t), \\
=R_{a} i_{a}(t)+L_{a} \frac{d i_{a}(t)}{d t}+K_{b} \omega(t), \quad e_{b}(t)=K_{b} \omega(t)
\end{array}\right\}
$$$$
\frac{\Omega(s)}{E_{a}(s)}=\frac{K_{A} K_{t}}{J L_{a} s^{2}+\left(B L_{a}+J R_{a}\right) s+\left(B R_{a}+K_{t} K_{b}\right)}
$$

By substituting for the DC motor parameters in (10), The transfer function is:

$$
G_{p}(s)=\frac{189.6565}{0.0001486 s^{2}+76.3867 s+132.4162}
$$

\section{ATS-BAsEd Design OF I-PD CONTROLLER}

The ATS-based design of the I-PD controllers is illustrated in this section. Referring to Fig. 1, the AI 


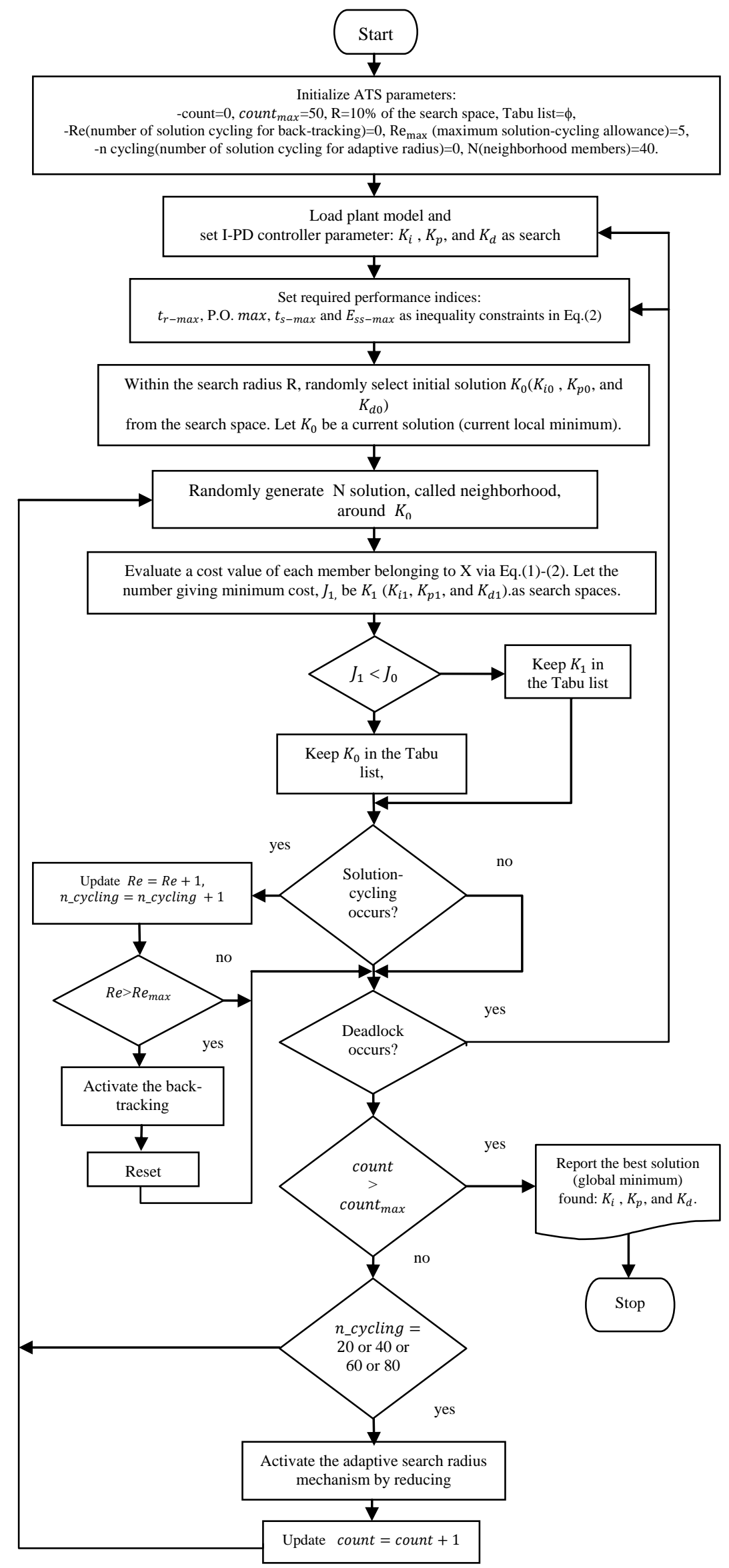

Fig.6. Diagram of the ATS's implementation for designing I-PD controller 
tuning block utilizes the ATS method. The parameter tuning process is repeatedly performed to minimize the cost function $J$ stated in (1)-(2) until the termination criterion is met. In this work, the maximum search round (count $\left._{\text {max }}\right)$ of the search process is the termination criterion. In each search round, 40 neighborhood members are randomly generated, and count $t_{\text {max }}$ is set as 50. Diagram of the ATS's implementation for designing I-PD controller as shown in Fig. 6.

The diagram in Fig. 6 reveals the search process of the ATS for designing PID and I-PD controllers. In this work, the ATS was coded in MATLABTM for running on an Intel(R) Core (TM) i5-2450M CPU@ 2.5 GHz, 4 Gbytes RAM ,500 Gbytes HD. The flow diagram gives a clear view of the proposed method for the readers to follow. For more details of the back-tracking and the adaptive search radius mechanisms, the readers should consult the references [23, 24].

\section{SIMULATION AND EXPERIMENTAL RESULTS}

\section{A. Simulation Results}

In this sub-section, after the search process stop, the optimal PID and I-PD parameters are successfully obtained as summarized in Table 1-3. The simulation results of DC Motor Speed Controlled system with I-PD controller designed by the ATS method in (1) shown in Fig. 7 will be confirmed by the experimental results as described in next sub-section.

Table 1. Results of two controllers test parameters

\begin{tabular}{|c|c|c|c|}
\hline \multirow{2}{*}{ Controllers } & \multicolumn{3}{|c|}{ Parameters } \\
\cline { 2 - 4 } & $K_{p}$ & $K_{i}$ & $K_{d}$ \\
\hline PID & 9.976440 & 12.821038 & 0.000551 \\
\hline I-PD & 3.031736 & 19.989464 & 0.006679 \\
\hline
\end{tabular}

Table 2. Results of PID controller test parameters

\begin{tabular}{|c|c|c|c|c|}
\hline \multicolumn{5}{|c|}{ System responses } \\
\hline$t_{r}(\mathrm{sec})$. & $t_{s}(\mathrm{sec})$. & $M_{p}(\%)$ & $E_{s s}(\%)$ & $t_{\text {reg }}(\mathrm{sec})$. \\
\hline 0.1562 & 0.8530 & 15.654 & 0.00 & 2.1246 \\
\hline
\end{tabular}

Table 3. Results of I-PD controller test parameters

\begin{tabular}{|c|c|c|c|c|}
\hline \multicolumn{5}{|c|}{ System responses } \\
\hline$t_{r}(\mathrm{sec})$. & $t_{s}(\mathrm{sec})$. & $M_{p}(\%)$ & $E_{s s}(\%)$ & $t_{\text {reg }}(\mathrm{sec})$. \\
\hline 0.2146 & 0.9140 & 11.228 & 0.00 & 1.2652 \\
\hline
\end{tabular}

Referring to Table 1-3, as simulation results, it was found that the ATS can provide the optimal PID and I-PD parameters satisfying the constraints in (2). For the system responses in Fig. 7. By comparison, the controlled system with the I-PD provides significantly better responses with smaller overshoot and faster regulating time once compared to that with the parallel PID controller.

System responses obtained by the I-PD designed by the ATS will be compared with those obtained by basic parallel PID controller designed by the ATS. After the search process stopped, the optimal PID and I-PD parameters are successfully achieved as declared in Table 1-3. Their corresponding system responses are also reported in Table 1 , where $t_{r}$ is rise time, $t_{s}$ is settling time and $t_{\text {reg }}$ is regulating time. The step command and step disturbance responses of DC motor speed control system with PID and I-PD controllers are depicted in Fig.7.

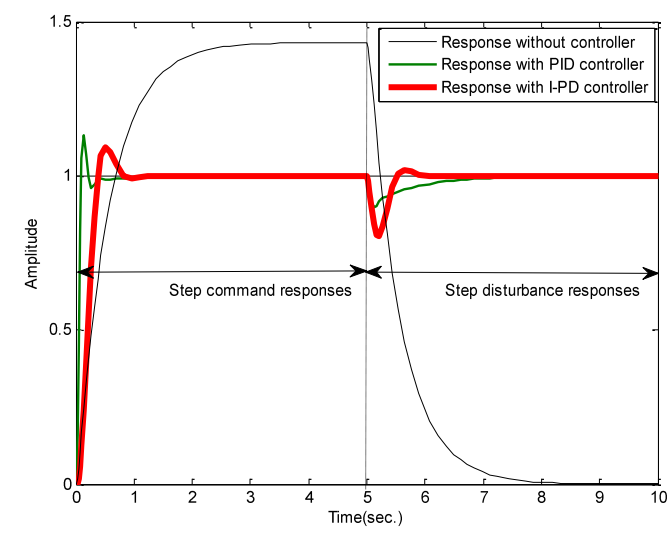

Fig.7. System responses without and with PID and I-PD designed by ATS.

\section{B. Experimental Results}

The ATS is applied to design the PID and I-PD controllers for the DC motor speed control, the proportional and derivative kick, the PID controller produces much greater control signal than the I-PD does. This causes the serious problem once implemented. Therefore, the I-PD controller is more practical for realworld implementation. In this work the operating speed of 1260,1400 , and $1540 \mathrm{rpm}$ with no load and full load conditions. To confirm the simulation result, the experimentation of DC motor speed control system need to be done. The PID and I-PD controllers designed by the ATS are implemented by the TMS320F28335 DSP controller board $[40,41]$ shown in Fig. 8 as the real time embedded control system. The TMS320F28335 DSP controller board consist of a 32-bit CPU and a singleprecision 32-bit floating-point. The $150 \mathrm{MHz}$ system clock is provided by an on-chip oscillator. The kit includes a peripheral explorer board and a control CARD with the TMS320F28335 MCU. The board includes many hardware-bas peripheral components for interacting with the various peripherals common to C2000 MCUs, such as the ADC, PWMs, eCAP, I2C, CAN, SPI, McBSP and TMS320F28335 DSP controller board is designed to interface with MATLAB/Simulink running on PC.

The DC motor speed control system is developed as the testing rig by using digital signal controller technology as shown in Fig. 9 for perform the experimental results. The electric load is applied to the load disturbance.

The first step, according to PID controller designed by the ATS can be implemented due to the high values of control gains. From Fig. 10, it was found at 1,260 rpm that the system response provides $t_{r}=420 \mathrm{~ms}, t_{s}=620$ $\mathrm{ms}, M_{p}=12.329 \%, E_{s s}=0.00 \mathrm{~ms}, t_{r e g}=500 \mathrm{~ms}$, Once upon a time comparable to the simulation results, the 
system output of experimental results gives slower response.

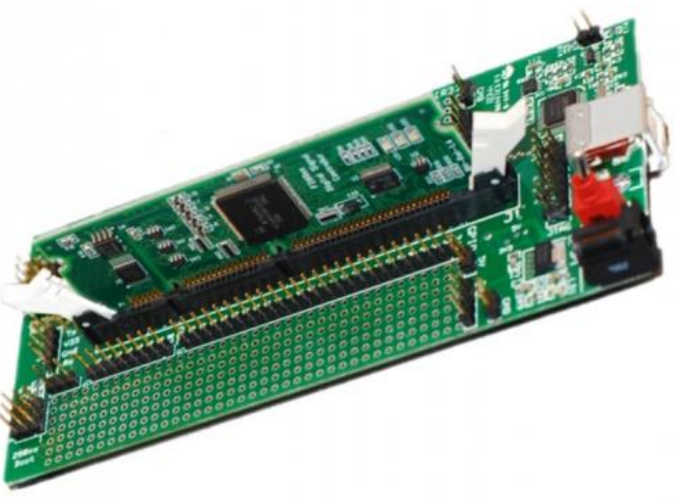

Fig.8. The TMS320F28335 DSP controller board.

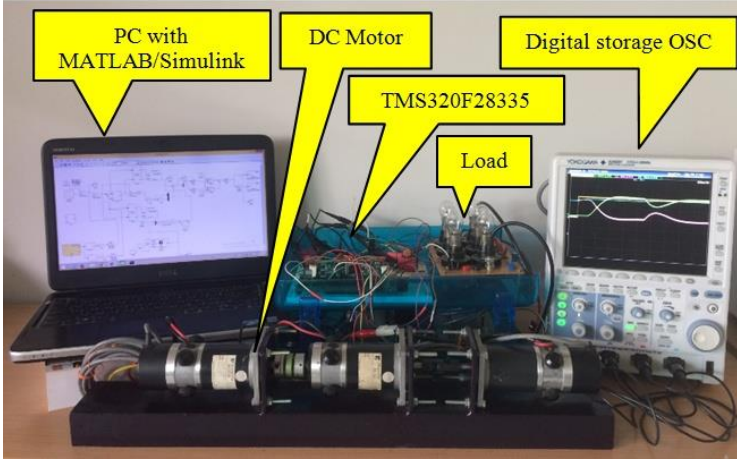

Fig.9. Testing rig of DC motor speed control system.

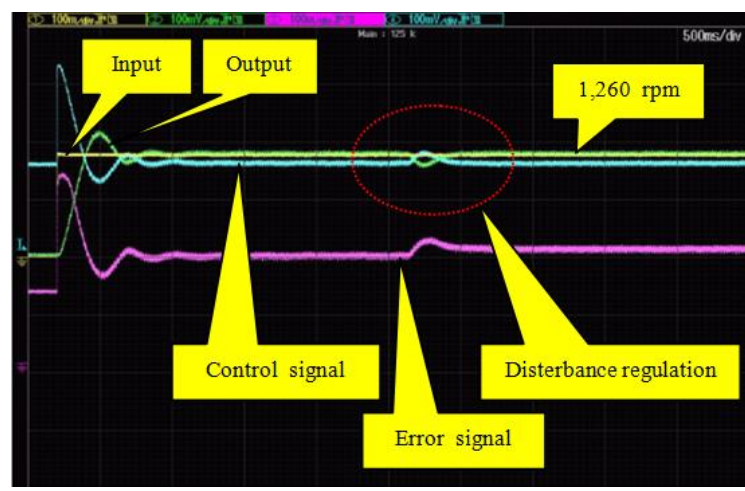

Fig.10. System responses of DC motor speed control system with PID controller.

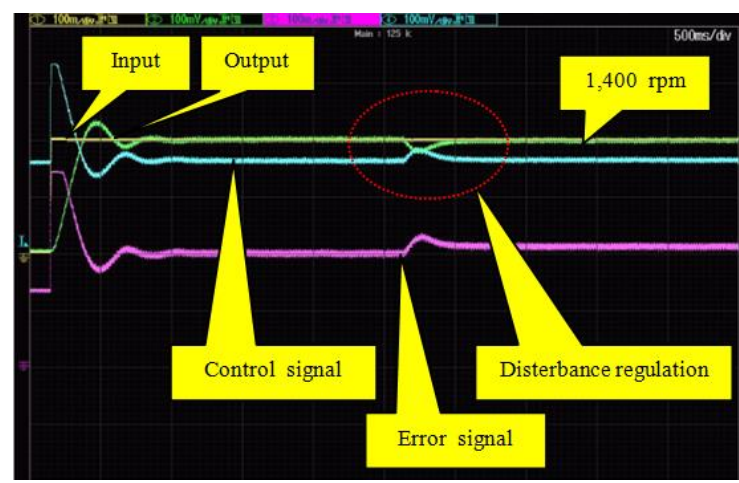

Fig.11. System responses of DC motor speed control system with PID controller.
The next step, according to PID controller designed by the ATS can be implemented due to the high values of control gains. From Fig. 11, it was found at 1,260 rpm that the system response provides $t_{r}=420 \mathrm{~ms}, t_{s}=620$ $\mathrm{ms}, M_{p}=12.329 \%, E_{s s}=0.00 \mathrm{~ms}, t_{r e g}=500 \mathrm{~ms}$, Once upon a time comparable to the simulation results, the system output of experimental results gives slower response.

The last step, according to PID controller designed by the ATS can be implemented due to the high values of control gains. From Fig. 12, it was found at 1,260 rpm that the system response provides $t_{r}=420 \mathrm{~ms}, t_{s}=620$ $\mathrm{ms}, M_{p}=12.329 \%, E_{s s}=0.00 \mathrm{~ms}, t_{r e g}=500 \mathrm{~ms}$, Once upon a time comparable to the simulation results, the system output of experimental results gives slower response.

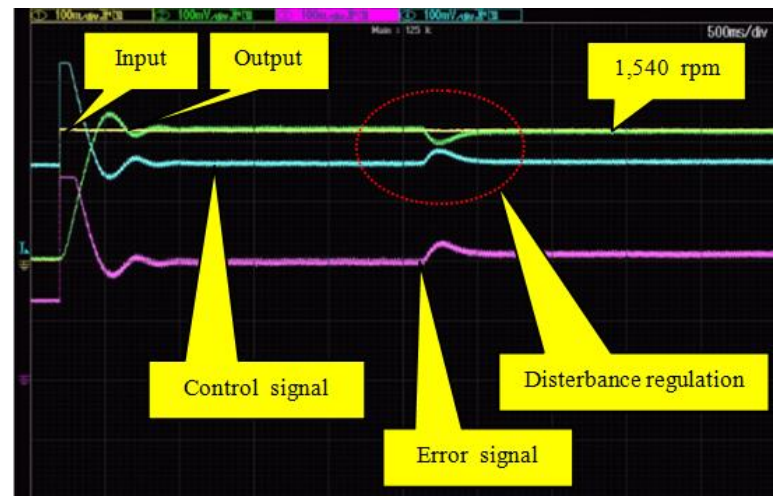

Fig.12. System responses of DC motor speed control system with PID controller.

The experimental result of DC motor speed control system with I-PD controller designed by the ATS is depicted in Fig.13-15. This proposed method is tested with the DC motor, 1260, 1400, $1540 \mathrm{rpm}$. The simulation results was compared in this case.

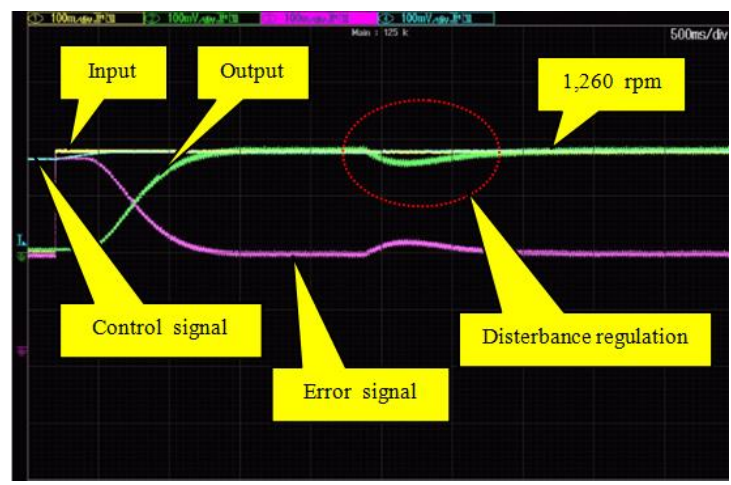

Fig.13. System responses of DC motor speed control system with I-PD controller.

The first step, according to I-PD controller designed by the ATS can be implemented due to the high values of control gains. From Fig. 13, it was found at 1,260 rpm that the system response provides $t_{r}=1,000 \mathrm{~ms}, t_{s}=1,100$ $\mathrm{ms}, \quad M_{p}=0.00 \%, E_{s s}=0.00 \mathrm{~ms}, t_{r e g}=520 \mathrm{~ms}$, Once upon a time comparable to the simulation results, the system output of experimental results gives slower response.

I.J. Intelligent Systems and Applications, 2017, 9, 69-78 


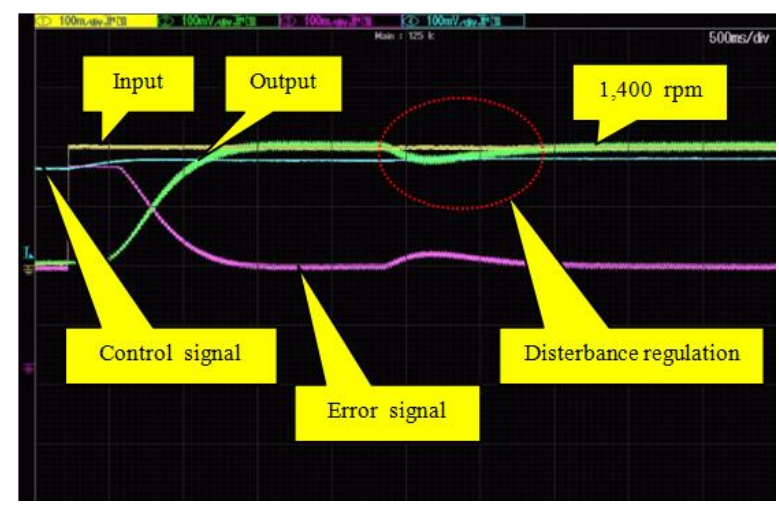

Fig.14. System responses of DC motor speed control system with I-PD controller.

The next step, according to I-PD controller designed by the ATS can be implemented due to the high values of control gains. From Fig. 14, it was found at 1,400 rpm that the system response provides $t_{r}=1,000 \mathrm{~ms}, t_{s}=1,100$ $\mathrm{ms}, M_{p}=0.00 \%, E_{s s}=0.00 \mathrm{~ms}, t_{\text {reg }}=600 \mathrm{~ms}$, Once upon a time comparable to the simulation results, the system output of experimental results gives slower response.

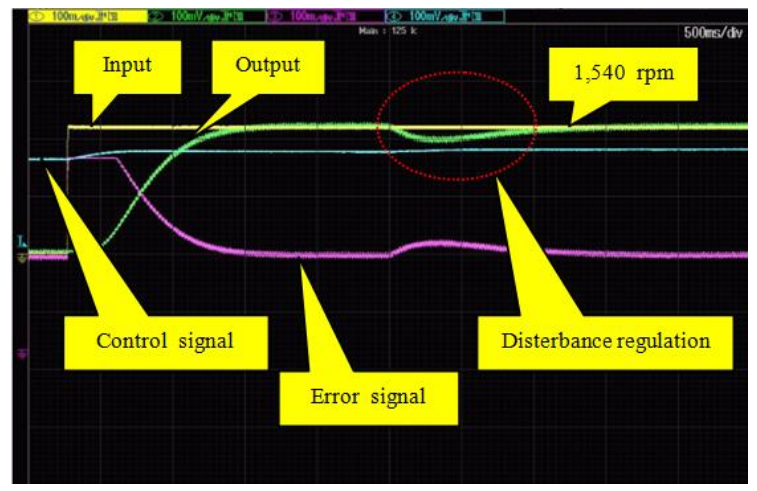

Fig.15. System responses of DC motor speed control system with I-PD controller.

The last step, according to I-PD controller designed by the ATS can be implemented due to the high values of control gains. From Fig. 15, it was found at 1,540 rpm that the system response provides $t_{r}=1,000 \mathrm{~ms}, t_{s}=1,100$ $\mathrm{ms}, M_{p}=0.00 \%, E_{s s}=0.00 \mathrm{~ms}, t_{\text {reg }}=1,000 \mathrm{~ms}$, Once upon a time comparable to the simulation results, the system output of experimental results gives slower response.

\section{CONCLUSIONS}

The optimal I-PD controller design for DC motor speed control system by the adaptive tabu search (ATS) has been proposed in this paper. The I-PD, one of the modified versions of the PID controller, has been proposed to avoid the proportional and derivative kick occurred during set-point change and to reduce undesirable overshoot. As the powerful metaheuristic optimization technique, the ATS has been conducted. The ATS could provide optimal PID and I-PD controllers for DC motor speed control system. By comparison, it can be concluded that the controlled system with I-PD provided better responses with smaller overshoot and faster regulating time as well as practical control signal.

\section{ACKNOWLEDGMENT}

The authors wish to thank the anonymous reviewers for their constructive comments that greatly contributed to improve the final version of the paper. Also, they wish to thank the Editors for their generous comments and support during the review process.

\section{REFERENCES}

[1] N. Minorsky, Directional stability of automatically steered bodies. American Society of Naval Engineering, 34, 284, 1922.

[2] S. Bennett, Development of the PID controller. IEEE Control System Magazine, 1955, pp. 58-65.

[3] S. P. Yadav and V.K. Tripathi, A Case Study of DC Motor Speed Control with PID Controller through MAT LAB. International Journal of Advanced Research in Computer and Communication Engineering, 2016, pp.1008-1011.

[4] A. Nawikavatan, S. Tunyasrirut and D. Puangdownreong, "Application of intensified current search to multiobjective PID controller optimization," International Journal of Intelligent Systems and Applications (IJISA), Vol. 8 No.11, pp. 51-60, 2016. DOI: 10.5815/ijisa.2016.11.06.

[5] Y. Lingzhi, Z. Chengdong and W. Genping, "Research of self-tuning PID for PMSM vector control based on improved KMTOA," International Journal of Intelligent Systems and Applications (IJISA), Vol. 9 No.3, pp. 60-67, 2017. DOI: 10.5815/ijisa.2017.03.08.

[6] M.A. Johnson and M.H. Moradi, PID Control: New Identification and Design Methods, Springer, London, UK, 2005.

[7] T. Sato and A. Inoue, A design method of multirate I-PD controller based on multirate generalized predictive control law. SICE Annual Conference, 2004, pp.17-22.

[8] T. Woo, J.S. Kim and Y.C. Kim, Digital control of UPS inverter with time response specifications. KIEE Trans., on Electrical Machinery and Energy Conversion Systems, 5-B(2), 2005, pp.196-203.

[9] S. Cheol, S. Kim Choo, K. Kang Han, Y. Bae Sung, J. Cho Hyung and Park, A Design of I-PD controller using CDM. International Conference on Control, Automation and Systems, 2007, pp.477-480.

[10] H. KONDO. and Y. OCHI, I-PD Flight Controller Design based on Integral-Type Optimal Servomechanism. SICE Journal of Control, Measurement, and System Integration, Vol. 3, No. 6, November 2010 pp. 448-455.

[11] S. Mohizuki and H. Ichihara, I-PD controller design based on generalized KYP lemma for ball and plate system. European Control Conference (ECC), 2013, pp.28552860.

[12] W. Chatrattanawuth, N. Suksariwattanagul, T. Benjanarasuth and J. Ngamwiwit, Fuzzy I-PD controller for level control. SICE-ICASE International Joint Conference, 2006, pp. 5649-5652.

[13] D. Sandhya, R.B. Amarendra, and K.A.G. Rao, Fuzzy I$\mathrm{PD}$ and fuzzy PID control of non-linear systems. International Conference on Control, Automation, Communication and Energy Conservation, 2009, pp. 1-6

[14] S.J.S. Prasad, S. Varghese and P.A. Balakrishnan, Particle swarm optimized I-PD controller for second order time 
delayed system. International Journal of Soft Computing and Engineering (IJSCE), 2(1), 2012, pp.299-302.

[15] S.J.S. Prasad and P.A. Balakrishnan, PSO based I-PD controller for barrel temperature control in plastic injection molding system. European Journal of Scientific Research, 80(3), 2012 pp.351-357.

[16] V. Rajinikanth and K. Latha, I-PD controller tuning for unstable system using bacterial foraging algorithm: a study based on various error criterion. Applied Computational Intelligence and Soft Computing, 2012, pp.1-10.

[17] H. Ikeda and H. Tsuyoshi, Design of m-IPD controller of multi-inertia system using differential evolution. The International Power Electronics Conference, 2014, pp. 2476-2482.

[18] S. J. Suji Prasad, R. Meenakumari and P. A. Balakrishnan, Optimization of I-PD controller parameters with multi objective particle swarm optimization, Journal of Theoretical and Applied Information Technology, 20th August 2014. Vol. 66 No.2, pp. 542-546.

[19] S. Sujitjorn, T. Kulworawanichpong, D. Puangdownreong and K-N. Areerak, Adaptive Tabu Search and Applications in Engineering Design, Frontiers in Artificial Intelligent and Applications, IOS Press, Amsterdam, Netherlands, 2006.

[20] K.-N. Areerak, T. Kulworawanichpong and S. Sujitjorn, Moving towards a new era of intelligent protection through digital relaying in power system. Lecture Notes in Artificial Intelligence, 3215, 2004, pp.1255-1261.

[21] D. Puangdownreong and S. Sujitjorn, Image approach to system identification. WSEAS Transactions on Systems, 5(5), 2006, pp. 930-938.

[22] D. Puangdownreong and S. Sujitjorn, Obtaining an optimum PID controller via adaptive tabu search. Lecture Notes in Computer Science, 4432(2), 2007, 747-755.

[23] D. Puangdownreong, T. Kulworawanichpong, and S. Sujitjorn, Finite Convergence and Performance Evaluation of Adaptive Tabu Search. Lecture Notes in Artificial Intelligence, Vol. 3215. Springer-Verlag, Berlin Heidelberg (2004) 710-717.

[24] D. Puangdownreong, K-N. Areerak, A. Srikaew, S. Sujitjorn, and P. Totarong, System Identification via Adaptive Tabu Search. Proc. IEEE Int. Conf. on Industrial Technology (ICIT'02), Vol. 2 (2002) 915-920.

[25] R. Firoozian, Servo Motors and Industrial Control Theory, Springer International Publishing Switzerland, 2014.

[26] P. Vas, Parameter Estimation, Condition Monitoring and Diagnosis of Electrical Machines, Oxford University Press, 1993.

[27] L. Ljung, System identification: Theory for the user, Prentice-Hall, 1987.

[28] P. Eykhoff, System identification: Parameter and State Estimation, John Wiley \& Sons, 1974.

[29] F. Piltan, S. TayebiHaghighi and Nasri B. Sulaiman, "Comparative study between ARX and ARMAX system identification," International Journal of Intelligent Systems and Applications (IJISA), Vol. 9 No.2, pp. 25-34, 2017. DOI: $10.5815 /$ ijisa.2017.02.04.

[30] I. J. Leontaritis and S. A. Billings, Input-output parametric models for nonlinear systems (part I: deterministic nonlinear systems), Int. J. Control, 1985, 41(2), $303-328$.

[31] I. J. Leontaritis and S. A. Billings, Input-output parametric models for nonlinear systems (part II: stochastic nonlinear systems), Int. J. Control, 1985, 41(2), $329-344$.

[32] D. Puangdownreong, S. Sujitjorn and T.
Kulworawanichpong, Convergence analysis of adaptive tabu search, ScienceAsia Journal of the Science Society of Thailand, 2004, 30, 183-90.

[33] S. Sujitjorn, T. Kulworawanichpong, D. Puangdownreong and K-N. Areerak, Adaptive tabu search and applications in engineering design, Frontiers in Artificial Intelligent and Applications, IOS Press, Amsterdam, Netherlands, 2006.

[34] D. Puangdownreong, S. Sujitjorn, Obtaining an optimum PID controller via adaptive tabu search, Lecture Notes in Computer Science, 2007, 4432, 747 - 755.

[35] D. Puangdownreong, K-N. Areerak, K-L. Areerak, T. Kulworawanichpong, and S. Sujitjorn, Application of adaptive tabu search to system identification, The $24^{\text {th }}$ IASTED International Conference on Modelling, Identification, and Control (MIC2005), 2005, 178 - 183.

[36] T. Ketthong, C. Kiree, S. Tunyasrirut and D. Puangdownreong, Parameter identification of DC-servo motor by adaptive tabu search. The International Annual Symposium on Computational Science and Engineering (ANSCSE19), 2015, 79-83

[37] T. Ketthong, S. Tunyasrirut and D. Puangdownreong, ATS base I-PD controller optimization for DC motor speed control system, Global Engineering \& Applied Science Conference, 2015, pp.91-98.

[38] K. Ogata, Modern Control Engineering, Prentice Hall, New Jersey, 2010.

[39] D. Puangdownreong, Current search: performance evaluation and application to dc motor speed control system design, Intelligent Control and Automation, 2013, $4(1), 42-54$.

[40] http://www.ti.com/lit/er/sprz272k/sprz272k.pdf, access on January, 2017.

[41] http://www.ti.com/lit/sg/sprb176ad/sprb176ad.pdf, access on January, 2017.

\section{Authors' Profiles}

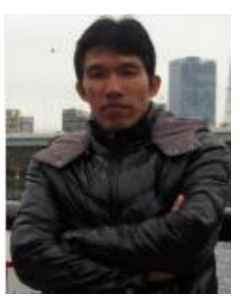

Thanet Ketthong received his B.Eng. degree in electronics and telecommunication engineering from Pathumwan Institute of Technology (PIT), Bangkok, Thailand, in 2006 and M.Eng. degree in electrical engineering from King Mongkut's University of Technology Thonburi (KMUTT), Bangkok, Thailand, in 2011, respectively. Now, he is a D.Eng candidate in electrical engineering, faculty of engineering, Pathumwan Institute of Technology (PIT), Bangkok, Thailand. Since 2012, he has been an the lecturer at Department of Electrical Engineering, Faculty of Engineering, Dhonburi Rajabhat University, Bangkok, Thailand. His research interests include system identification, intelligent control, power electronics, motor drives, image processing, biomedical and digital signal processing.

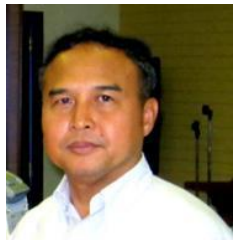

Satean Tunyasrirut received his B.S.I.Ed. in electrical engineering and M.S. Tech.Ed. in electrical technology from King Mongkut's Institute of Technology North Bangkok (KMITNB), Bangkok, Thailand in 1986 and 1994, respectively. He received the B.Eng in electrical Engineering from Rajamangala University of Technology 
Thanyaburi (RMUTT), Thailand, in 2003 and D.Eng in electrical engineering from King Mongkut's Institute of Technology Ladkrabang (KMITL), Bangkok, Thailand, in 2007. In 1995, he was awarded with the Japan International Cooperation Agency (JICA) scholarship for training the Industrial Robotics at Kumamoto National College of Technology, Japan. Since 2005, he has been an associated Professor at Department of Instrumentation Engineering, Pathumwan Institute of Technology (PIT), Bangkok, Thailand. His research interests include modern control, intelligent control, power electronics, electrical machine and motor drives.

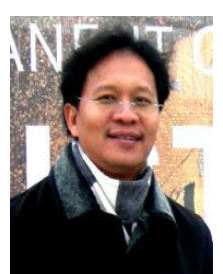

Deacha Puangdownreong received his the B.Eng. degree in electrical engineering from South-East Asia University (SAU), Bangkok, Thailand, in 1993, M.Eng. degree in control engineering from King Mongkut's Institute of Technology Ladkrabang (KMITL), Bangkok, Thailand, in 1996, and Ph.D. degree in electrical engineering from Suranaree University of Technology (SUT), Nakhon Ratchasima, Thailand, in 2005, respectively. Since 1994, he has been with the Department of Electrical Engineering, Faculty of Engineering, South-East Asia University, where he is currently an associated professor of electrical engineering. He has authored 4 books and published as authors and coauthors of more than 120 research and technical articles in peer-reviewed journals and conference proceedings nationally and internationally. He has been listed in Marquis Who's Who in the World, Marquis Who's Who in Science and Engineering, and Top 100 Engineers-2011 in International Biographical Center, Cambridge, UK. His research interests include control synthesis and identification, metaheuristics and search algorithms as well as their engineering applications.

How to cite this paper: Thanet Ketthong, Satean Tunyasirut, Deacha Puangdownreong, "Design and Implementation of I-PD Controller for DC Motor Speed Control System by Adaptive Tabu Search", International Journal of Intelligent Systems and Applications(IJISA), Vol.9, No.9, pp.69-78, 2017. DOI: 10.5815/ijisa.2017.09.08 